\title{
Occupational Heat Stress in the Floriculture Industry of Ethiopia: Health Risks and Productivity Losses
}

\section{Belay Simane ${ }^{*}$, Abera Kumie ${ }^{2}$, Kiros Berhane ${ }^{3}$, Jonathan Samet ${ }^{4}$, Tord Kjellstrom5 Jonathan Patz ${ }^{6}$}

${ }^{1}$ College of Development Studies, Addis Ababa University, Addis Ababa, Ethiopia

${ }^{2}$ School of Public Health, Addis Ababa University, Addis Ababa, Ethiopia

${ }^{3}$ Mailman School of Public Health, Columbia University, New York, NY, USA

${ }^{4}$ Colorado School of Public Health, Aurora, CO, USA

${ }^{5}$ University of Wisconsin-Madison, Madison, WI, USA

${ }^{6}$ Health and Environment International Trust, Mapua, Nelson, New Zealand

Email: ^belay.simane@aau.edu.et

How to cite this paper: Simane, B., Kumie, A., Berhane, K., Samet, J., Kjellstrom, T. and Patz, J. (2022) Occupational Heat Stress in the Floriculture Industry of Ethiopia: Health Risks and Productivity Losses. Health, 14, 254-271.

https://doi.org/10.4236/health.2022.142020

Received: October 2, 2021

Accepted: February 25, 2022

Published: February 28, 2022

Copyright $\odot 2022$ by author(s) and Scientific Research Publishing Inc. This work is licensed under the Creative Commons Attribution International License (CC BY 4.0).

http://creativecommons.org/licenses/by/4.0/

\section{Open Access}

\begin{abstract}
Background: The Ethiopian flower industry is growing fast with successful diversification of export products under greenhouse structures. Higher temperatures in the greenhouses pose a serious threat to the health of workers and add to the risk of occupational heat stress. Excessive heat in workplace settings also reduces work capacity and labour productivity. This study aims to investigate the level of heat exposure, and workers' and managers' perceptions and behavioural responses towards extreme heat exposure in a warming climate. Methods: We used the Wet Bulb Globe Temperature (WBGT) measured in representative greenhouses to capture the heat exposure during hotter and cooler seasons following ISO 7243 (generally risk of heat stress occurs when WBGT exceeds $26^{\circ} \mathrm{C}$ ). A comparative cross-sectional study design with a stratified sampling method was used to assess occupational heat stress and workers' perceptions of the impact of heat on their health and productivity in six different floriculture greenhouses in Ethiopia representing three different agro-ecologies and products. A questionnaire survey was conducted (30 managers/supervisors and 305 workers; $76.1 \%$ female) to capture perceptions on heat exposures, symptoms of potential health impacts, productivity losses and coping mechanisms. Results: Heat exposure varied across different agroecologies, product types and greenhouse materials with a median WBGT Index of $25.5^{\circ} \mathrm{C}$ and a range from $18.1^{\circ} \mathrm{C}$ to $31.5^{\circ} \mathrm{C}$. The impact of heat stress also varied across different employment sectors and geographical regions. Overall, workers in cut-flower greenhouses are exposed to higher
\end{abstract}


than recommended WBGT Index $\left(26^{\circ} \mathrm{C}\right)$ for 3 - 6 working hours daily. $65 \%$ of the managers reported that heat stress has a significant impact on the workers' labour productivity, but do not have guidance about working in hot conditions. Workers reported more heat-related health issues and reduced productivity, especially in the mid-altitude greenhouses. About $50 \%$ of the workers reported that heat exposure decreased work productivity during hot hours. Sweating, exhaustion, heat-rashes, dehydration, crumps, nausea and headache were self-reported health issues. Labour productivity losses ranged from no loss to $19.5 \%$ in the mid- and low-altitudes. Conclusions and Recommendations: Excessive workplace heat in the greenhouses is both an occupational health hazard and detrimental to productivity in the floriculture industry. However, the level of understanding and actions on the ground regarding occupational heat stress are low. The code of conduct in place now does not consider the occupational heat stress issues. Multiple actions (engineering, management, training and policy-related recommendations) have to be implemented by Ethiopian Horticultural Producers and Exporters Association (EHPEA) and farm owners to mitigate heat stress and loss of productivity. Designing and implementing these heat prevention strategies and incorporating them into the code of conduct is in the interests of both employers and employees.

\section{Keywords}

Floriculture, Heat Index, Health Impacts, Occupational Heat Stress, Productivity Losses

\section{Introduction}

Global warming is expected to result in an increase in work-related heat stress and a decrease in productivity, and to cause job and economic losses. Concerns over workplace heat exposure were first raised in the Fourth Assessment Report of the Intergovernmental Panel on Climate Change [1] and received a stronger focus in the Fifth Assessment Report [2]. The IPCC's Fifth Assessment Report confirmed that labour productivity impacts could result in output reductions in affected sectors exceeding $20 \%$ during the second half of the century-the global economic cost of reduced productivity may be more than 2 trillion USD by 2030 [2]. An increase in heat stress resulting from global warming is projected to lead to global productivity losses equivalent to 80 million full-time jobs in the year 2030, according to a new report from the International Labour Organization [3].

Regional and temporal variability of climate is the major determinant of agricultural production in Ethiopia. Mean annual temperature has risen by $1.3^{\circ} \mathrm{C}$ between 1960 and 2006, an average rate of $0.28^{\circ} \mathrm{C}$ per decade [4]. Daily temperature observations show an increasing frequency of both hot days and hot nights. Climate models suggest that Ethiopia will see further warming in all seasons of between $0.7^{\circ} \mathrm{C}$ and $2.3^{\circ} \mathrm{C}$ by the $2020^{\circ}$ and of between $1.4^{\circ} \mathrm{C}$ and $2.9^{\circ} \mathrm{C}$ by the 
2050s [4] [5]. An increase in rainfall variability is also predicted, with a rising frequency of both extreme flooding and droughts that could seriously affect agricultural production. Agricultural production and productivity including the floriculture sector are related to the performance of improved and adaptable technologies, which are destined for a particular environmental condition [6] [7].

In Ethiopia, commercial flower production is practiced mainly under greenhouse structures. Given the diversity of climatic conditions and altitudes in Ethiopia, different types of flower species and varieties are grown and each type of flower has different optimal conditions varying by light intensity, light exposure, soil acidity, water needs and temperature amongst other factors. Under greenhouses, for most commercial varieties, the best quality of flower shoots, in terms of stem length, diameter of leaf area and flower bud size, is obtained at $28^{\circ} \mathrm{C}$. As temperature increases, the periods from cut back to flowering became shorter; stem became shorter, diameter and leaf area smaller, flower weight decreases and adjoins with fewer and smaller petals [8]. The most important environmental parameters that need to be controlled for optimal greenhouse climate are temperature, light, relative humidity, and carbon dioxide $\left(\mathrm{CO}_{2}\right)$. Temperature is the most important single parameter as it has a significant role in plant growth and development. The optimal temperature depends on the plant species grown and desired level of photosynthetic activity.

The Ethiopian flower industry is growing fast with successful diversification of export products (Figure 1). The country is now the second-largest flower exporter in Africa, with 84 active flower farms on 1426 hectares [9]. The floriculture industry has also had a huge impact on Ethiopia's economy and society; most significantly on job creation. The area cultivated is expected to grow to 3000 hectares in the coming five years and the revenue is projected to increase to $\$ 550$ million [10]. Cut-flower production is a labour-intensive activity, since few tasks can be mechanized, making labour costs a significant factor. The workforce in the flower industry is predominantly female, as more than $80 \%$ of workers are female [8]. Occupational heat stress is expected to be a significant problem in flower greenhouses in Ethiopia. Excessive heat while working, generally at temperatures above $35^{\circ}$ Celsius, creates occupational health risks and reduces work capacity and labour productivity [11].

Given the diversity of climatic conditions and altitudes in Ethiopia, different basic types of rose varieties are grown in greenhouse structures and each type of flower has different optimal conditions varying by light intensity, light exposure, soil acidity, water needs and temperature amongst other factors. For most commercial varieties, the best quality of flower shoots, in terms of stem length, diameter of leaf area and flower bud size, is obtained at $28^{\circ} \mathrm{C}$. As temperature increases, the periods from cutting to flowering became shorter; stems became shorter, diameter and leaf area smaller, flower weight decreases and adjoins with fewer and smaller petals [8]. Temperature can also affect plant quality. Too high temperature reduces plant growth, eventually resulting in plant wilting and death whereas too low temperature limits plant growth. 


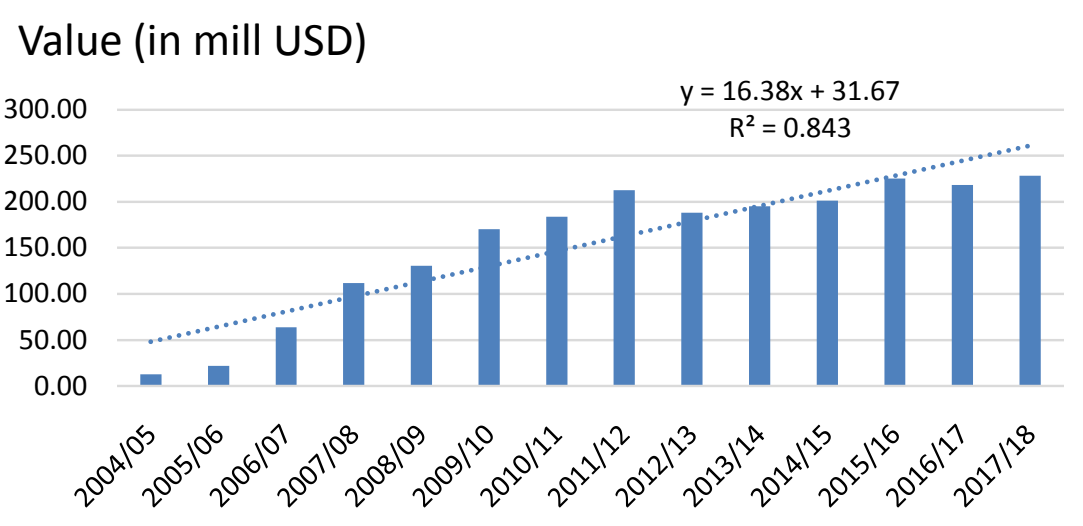

Figure 1. Time trend of economic value of the Ethiopian Floriculture industry.

Occupational heat stress (excessive workplace heat) is a well-known occupational health and productivity danger in the agriculture sector [12] [13]. Excessive heat (generally when WBGT exceeds $26^{\circ} \mathrm{C}$ ) while working creates occupational health risks and reduces work capacity and labour productivity [14]. Exposure to hot environments and extreme heat can result in illnesses, including heat stroke, heat exhaustion, heat syncope, heat cramps, and heat rashes, or death [15]. Maintaining a core body temperature close to $37^{\circ} \mathrm{C}$ is essential for health and work efficiency, and excessive sweating as a result of high heat exposure while working creates a risk of dehydration [3]. Studies have shown that workers often only replace approximately half to two-thirds of the fluids lost through sweating at work when fluid is freely available. Excessive body temperature and/or dehydration causes "heat exhaustion", slower work, more mistakes while working, clinical heat effects [16] and increased risk of accidental injuries [17]. Heat stroke, which can be fatal in the absence of swift, effective treatment, is the most serious health risk posed by heat stress.

The International Organization for Standardization (ISO) has adopted assessment methods for the risk of heat stress [18]. The most commonly used is the wet-bulb globe temperature (WBGT) index, which is calculated by measuring the natural wet-bulb temperature, the global temperature and the air temperature to estimate the effects of temperature, humidity, wind speed (wind chill) and visible and infrared radiation (usual sunlight) on humans.

The main objective of this paper is to present the findings of measured occupational heat stress exposure and perceived impacts of heat exposure on the health and productivity of workers in six different floriculture greenhouses in Ethiopia representing three different agroecologies and products.

\section{Methodology}

Occupational heat stress and workers' perceptions of the impact of heat on their health and productivity were studied in 6 different floriculture greenhouses representing three different agroecologies and two production systems (Table 1). 
Greenhouses from around three cities in Ethiopia (Holetta, DebreZeit and Ziway representing highland, midland and lowland agro-ecologies, respectively) were selected in consultation with the Ethiopian Horticulture Producers and Exporters Association (EHPEA). Farms that had been functional for the last 12 months prior to the study were eligible for the study. The selection of two farms from each agroecology was considered to cover diverse working conditions based on consultations with the Ethiopian Horticulture Producers and Exporters Association (EHPEA). Greenhouse structures and different production systems were also compared in terms of heat exposure.

The study used Wet Bulb Globe Temperature (WBGT) to capture heat exposure and a questionnaire survey to capture perceptions on heat exposures, symptoms of potential health impacts, productivity losses and coping mechanisms (Figure 2). Quantitative data on heat stress exposure were collected using the Wet Bulb Globe Temperature (WBGT, Ques Temp 34WI, USA) placed in each of the six greenhouses to capture the heat exposure during hotter (May) and cooler seasons (November) following the Organization of International Standards (ISO) screening method for evaluating heat stress [18]. WBGTs were positioned in the six greenhouses and were mounted at a height of $1.1 \mathrm{~m}$ using a tripod stand in a representative location without any obstruction. In every agroecology, one additional WBGT was mounted outside the greenhouses for control.

Table 1. Profile of the farms included in the study.

\begin{tabular}{|c|c|c|c|c|c|c|c|c|}
\hline Farm Name & Farm Location & $\begin{array}{l}\text { Agro } \\
\text { ecology }\end{array}$ & $\begin{array}{l}\text { Owner } \\
\text { Citizen }\end{array}$ & $\begin{array}{l}\text { Year of } \\
\text { establishment }\end{array}$ & $\begin{array}{l}\text { Number of } \\
\text { workers }\end{array}$ & $\begin{array}{l}\text { Production } \\
\text { area }\end{array}$ & $\begin{array}{l}\text { Media of } \\
\text { production }\end{array}$ & $\begin{array}{l}\text { Standard } \\
\text { level }\end{array}$ \\
\hline Galica & Wolmera Woreda & Highland & France & 2008 & 340 & 15ha & soil & Gold \\
\hline $\begin{array}{l}\text { Hansa } \\
\text { Horticulture }\end{array}$ & Wolmera Birbisa Siba & Highland & Indian & 2005 & 240 & & Soil & no \\
\hline Roshanara & $\begin{array}{l}\text { Bishoftu Kality } \\
\text { Gebremahiber }\end{array}$ & Midland & Israel & 2003 & 360 & $15 \mathrm{ha}$ & soil & $\begin{array}{l}\text { MPS SQ, } \\
\text { ABC }\end{array}$ \\
\hline Dugda & $\begin{array}{l}\text { Bishoftu Akakikality } \\
\text { G/Mahiber }\end{array}$ & Midland & Ethiopians & 2005 & 355 & $20 \mathrm{ha}$ & soil & $\begin{array}{l}\text { EHPEA } \\
\text { bronze, ETI, } \\
\text { MPS }\end{array}$ \\
\hline $\begin{array}{l}\text { Abyssinia } \\
\text { flower }\end{array}$ & $\begin{array}{l}\text { Ejersajoro Keble } \\
\text { G.Mahiber }\end{array}$ & Lowland & Netherlands & 2015 & 779 & $15 \mathrm{ha}$ & Red Ash & $\begin{array}{l}\text { EHPEA } \\
\text { Silver, MPS } \\
\text { SQ, ABS, } \\
\text { internal } \\
\text { standard }\end{array}$ \\
\hline $\begin{array}{l}\text { Redfox } \\
\text { Ethiopia }\end{array}$ & Koka & Lowland & Netherlands & 2003 & 1500 & 41 ha & Red ash & $\begin{array}{l}\text { EHPEA } \\
\text { Gold, MPS } \\
\text { ABS, GAP, } \\
\text { UFDA, Fair } \\
\text { Trade }\end{array}$ \\
\hline
\end{tabular}




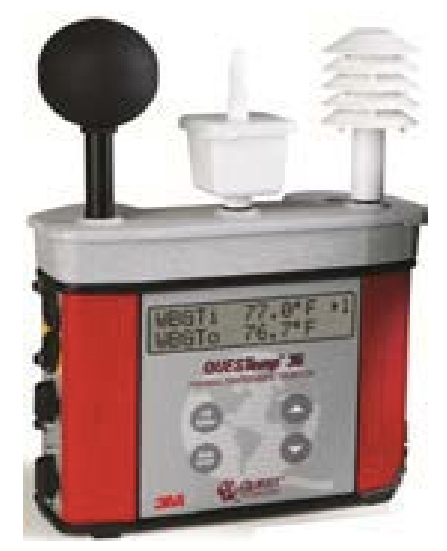

Figure 2. QuesTemp 36, Quest Technologies.

The WBGT index was specifically designed for work activity assessments and is calculated on the basis of temperature, humidity, air movement (wind speed) and radiated heat (sun or shade) [11]. The WBGT combines the effect of the four main thermal components affecting heat stress: air temperature, humidity, air velocity and radiation, as measured by the dry bulb, wet bulb and globe temperatures. Heat index was calculated for the six flower farms using WBGT as follows (there is no solar heat radiation on the workers).

$$
\mathrm{WBGT}=0.7 T_{w}+0.3 T_{d}
$$

where:

- $T_{w}=$ Natural wet-bulb temperature (combined with dry-bulb temperature indicates humidity);

- $T_{d}=$ Dry-bulb temperature (actual air temperature).

Qualitative data about the perceptions on heat exposures, heat-related health risks, productivity losses and adaptation mechanisms were collected using a cross-sectional interview-administered questionnaire survey between 28 May 2018 and 15 June 2018 using a modified version of HOTHAPS questionnaire [19] (fifteen managers and supervisors from the selected farms (five each) were selected purposively).

Based on the inclusion criteria, a total of 305 workers were selected randomly from a listing of workers representing the different work categories with $100 \%$ response rate (Table 2). Workers, who had worked at least for the last 6 months in the farm, were eligible for the study. Separate questionnaires were prepared for managers/supervisors and workers. Both questionnaires were pretested and translated to local languages and back translated to English. Experienced enumerators and supervisors were recruited and trained for two days. The questionnaire was pre-tested and adapted to the local circumstance.

Survey data were cleaned, coded and entered using a secure web-based database "Research Electronic Data Capture (REDCap)" and exported to SPSS version 20 for analysis. Structured data cleaning and checking any inconsistencies using the hard copy of the QRE were undertaken during data entry and cleaning. Descriptive statistical techniques were used to study the characteristics of the data. 
Table 2. Perceived understanding of heat exposure and its effects by managers and workers.

\begin{tabular}{cccc}
\hline Characteristics & Response & Managers & Workers \\
\hline $\begin{array}{c}\text { Exposure to excessive heat } \\
\text { during work }\end{array}$ & Yes & $7(22.6)$ & $264(86.6)$ \\
\hline $\begin{array}{c}\text { Awareness of any heat stress problems } \\
\text { during the past few (5) years }\end{array}$ & Yo & $24(77.4)$ & $39(12.8)$ \\
\hline $\begin{array}{c}\text { Knowledge about heat effects on } \\
\text { human health }\end{array}$ & No & $10(32.3)$ & $152(49.8)$ \\
\hline
\end{tabular}

Qualitative comparisons were made to assess the potential effect of exposures on awareness/occurrence of heat stress, loss of productivity and other health related impacts (as measured via the questionnaires), with proper adjustments for socio-demographic factors. Comparisons are made between locations from the three agroecologies.

Productivity loss due to heat stress was estimated as the percentage of direct work time decreasing by $5 \%$ when the WBGT index increased by $1^{\circ} \mathrm{C}$ above $26^{\circ} \mathrm{C}$ using the ISO standard following Yi, and Chan (5\% per degree WBGT) [20] and Kjellstrom et al., (20\% per degree WBGT) [12]. It is assumed that workers do not achieve work targets, due to fatigue/exhaustion, sickness/hospitalization, and/or wages are lost due to heat or heat-related illnesses.

Prior ethical clearance was obtained from the Addis Ababa University Institutional Review Board of the College of Health Sciences, Ethics and Research Committee of the School of Public Health. Also, permission letters were obtained from the Ethiopian Horticulture Producers and Exporters Association (EHPEA) and the farm owner. Participants of the study were selected randomly and engaged provided that informed consent was obtained from each participant to confirm their willingness after providing detailed explanations on the possible benefits and risks in participating in the survey.

\section{Results}

\subsection{Sociodemographic Characteristics}

Of the total worker respondents, $66.2 \%$ were working in the production sector while the rest were sprayers $(25.9 \%)$, packers $(11.1 \%)$, cold room workers $(4.3 \%)$ and transporters (33.4\%) (Table 3 ). The mean duration of working experience was $3.8(\mathrm{SD}=3.4)$ years. The majority $(76.1 \%)$ of the study participants were females. Their age ranged between 18 and 50 years few outside of that range (less than $18(1 \%)$ and more than $50(0.7 \%)$ years) with the mean age of $26.6(\mathrm{SD}=$ 7.3).

The age group 18 - 30 years, with a total of 239 (78.4\%), constituted most of the respondents. Regarding the educational status, most of the respondents had primary $(41.0 \%)$ and some secondary $(29.8 \%)$ education; while those with university level education comprised only 12 (3.9\%). Of the manager respondents, 
Table 3. Socio-demographic characteristics of the respondents (managers and workers) from the 6 flower farms.

\begin{tabular}{|c|c|c|c|c|}
\hline \multirow{2}{*}{ Characteristics } & \multicolumn{2}{|c|}{ Workers } & \multicolumn{2}{|c|}{ Managers } \\
\hline & Category & No (\%) & Category & No (\%) \\
\hline \multirow{5}{*}{ Job title } & Production & $202(66.2)$ & Farm manager & $4(12.9)$ \\
\hline & Sprayer & $79(25.9)$ & Production manager & $10(32.3)$ \\
\hline & Packer & $34(11.1)$ & Pack house manager & $8(25.8)$ \\
\hline & Cold-room & $13(4.3)$ & Sprayers' supervisor & $3(9.7)$ \\
\hline & Transporter & $102(33.4)$ & Others & $6(19.4)$ \\
\hline \multirow{2}{*}{ Sex } & Male & $73(23.9)$ & Male & $26(83.9)$ \\
\hline & Female & $232(76.1)$ & Female & $4(12.9)$ \\
\hline \multirow{5}{*}{ Age } & $<18$ & $3(1.0)$ & $<18$ & $1(3.2)$ \\
\hline & $18-30$ & $239(78.4)$ & $18-30$ & $14(45.2)$ \\
\hline & $31-50$ & $58(19.0)$ & $31-50$ & $8(25.8)$ \\
\hline & $>50$ & $2(0.7)$ & $>50$ & --- \\
\hline & Mean $\pm(S D)$ & $26.6 \pm 7.3$ & Mean $\pm(\mathrm{SD})$ & $30.5 \pm(6.6)$ \\
\hline \multirow{4}{*}{ Marital status } & Married & $175(57.4)$ & Married & $14(45.2)$ \\
\hline & Never Married & $109(35.7)$ & Never Married & $15(48.4)$ \\
\hline & Divorced & $16(5.2)$ & Divorced & $2(6.5)$ \\
\hline & Widowed & $4(1.3)$ & Widowed & - \\
\hline \multirow{5}{*}{ Level of Education } & No education & $69(22.6)$ & No education & - \\
\hline & Read and Write only & $8(2.6)$ & Read and Write only & - \\
\hline & Primary & $125(41.0)$ & Primary & - \\
\hline & Secondary & $91(29.8)$ & Secondary & $5(16.1)$ \\
\hline & University level & $12(3.9)$ & University level & $26(83.9)$ \\
\hline
\end{tabular}

production managers (32.3\%) and pack house managers (25.8\%) with university level education (83.9\%) constitute the majority.

\subsection{Heat Exposure}

Heat exposure varied across different agroecologies, product types and greenhouse materials (Figure 3(a)). While the WBGT index levels in the mid-altitude area that grows cut-flower are higher than the Threshold Limit Value (TLV), the WBGT index in the farms producing cuttings for pot plantation for propagations remained below the recommended TLV levels as the farms' temperature and humidity are auto-controlled. The wooden greenhouse structure material has also showed a significantly lower heat index as compared with that of steel structures.

Summary of hourly WBGT index average values by time is presented for the different farms (Figure 3(b)). These values reach levels beyond the international standard safe work values (ISO 7243:1989) during 10:00 AM to 3:00 PM. The median WBGT index was $25.5^{\circ} \mathrm{C}$ and ranged from $18.1^{\circ} \mathrm{C}$ to $31.5^{\circ} \mathrm{C}$ inside the 
greenhouses. In all agroecologies, it was hotter inside than outside the greenhouses. In all the ecologies, the heat exposure in the area outside of the greenhouses was significantly lower and below the ISO threshold value levels (Figure 4).

Overall, more than half (54.8\%) of the managers reported heat as only a mild problem while $22.6 \%$ reported that heat stress is a problem in their workplace (Table 2). Contrary to the managers, $86.6 \%$ of workers reported that heat stress is a problem, with $74.8 \%$ reporting that heat stress in the greenhouses does affect their health. Effect of heat exposure on their work and productivity is also well recognized. However, the majority (54.1\%) reported that their income is not decreasing despite their productivity losses. The provision of drinking water was the most commonly available heat prevention measure that is implemented in all farms.
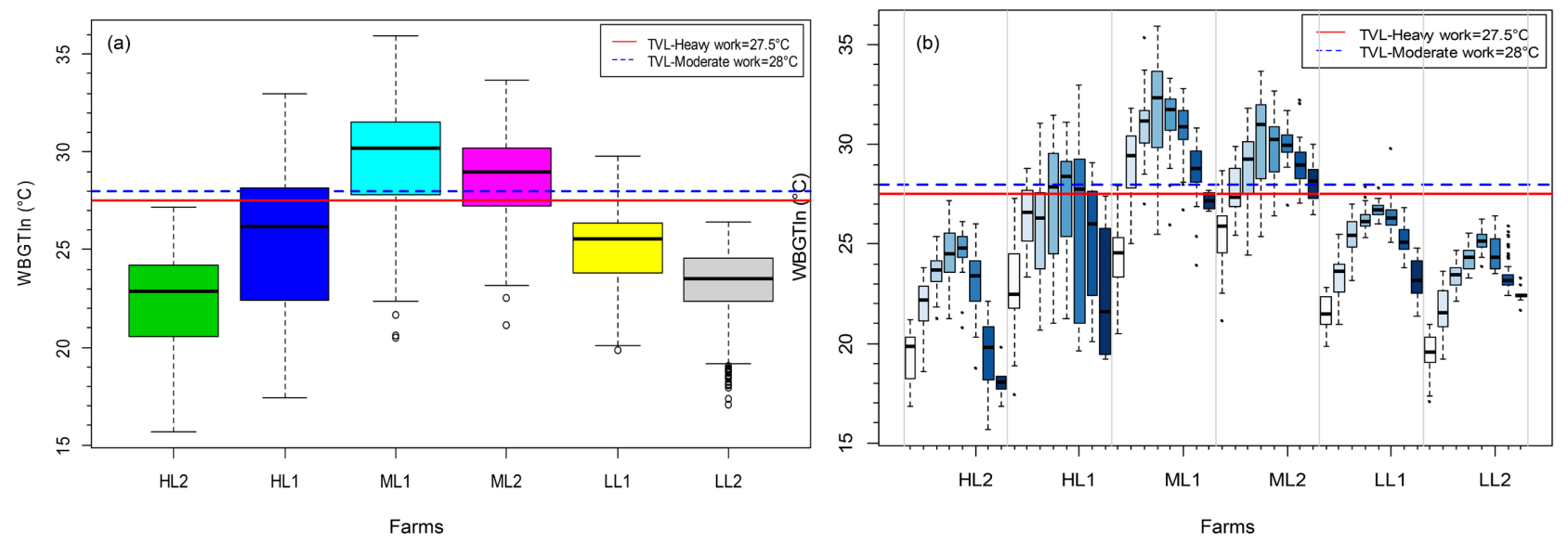

Figure 3. WBGT Index inside the greenhouses. (a) Average values by farms and agroecologies; (b) Hourly values between 9.00-16.00 hours (TLV: Threshold limit value; $\mathrm{HL}=$ Highland, $\mathrm{ML}=$ Midland and LL = Lowland farms studied).
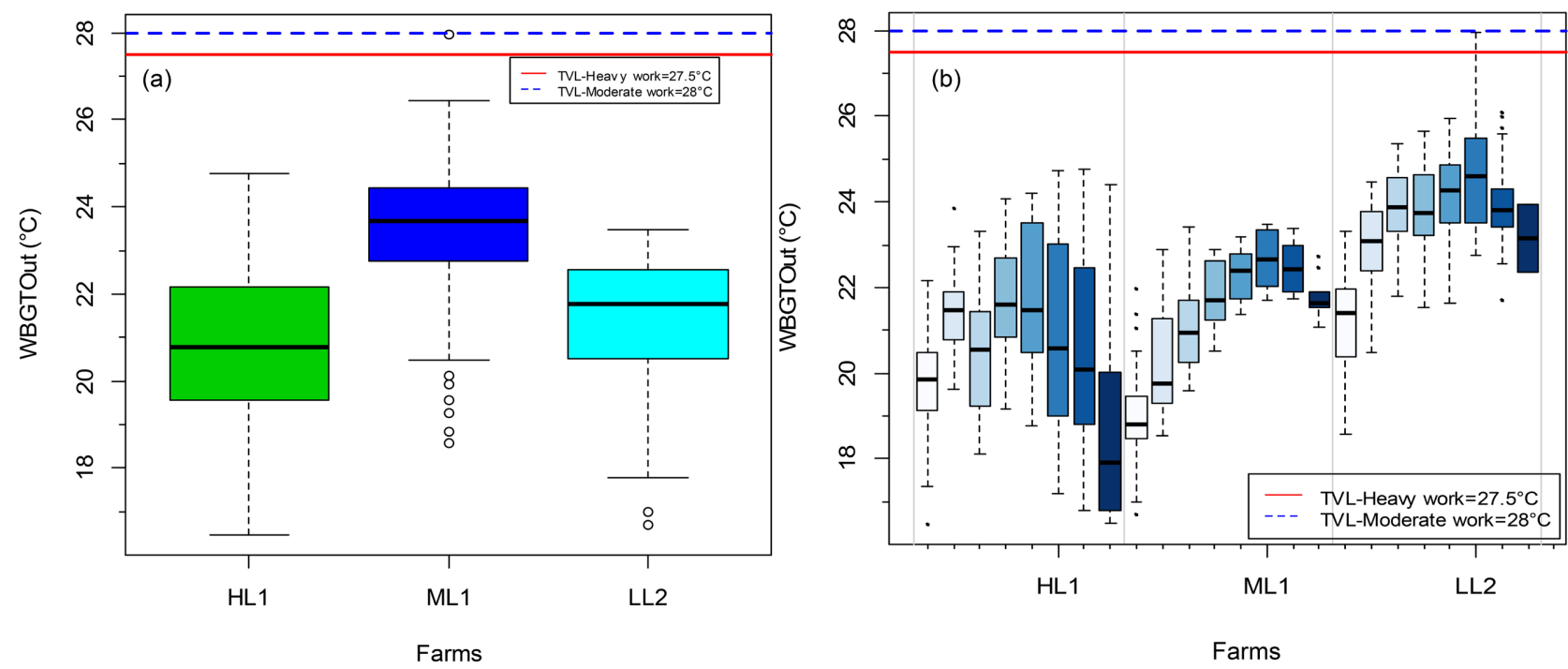

Figure 4. WBGT index outside the greenhouses. (a) Average values by agroecologies; (b) Hourly values time trends (TLV: Threshold limit value; $\mathrm{HL}=$ Highland, $\mathrm{ML}=$ Midland and $\mathrm{LL}=$ Lowland farms studied). 


\subsection{Health Impacts}

Heat stress, an environmental and occupational hazard, is associated with a spectrum of heat-related illnesses, including heat stroke, which can lead to death. The impact of heat stress varied across different agroecologies and production systems. Most participants felt that working in very hot weather could have various impacts on health. The health effects mentioned include sweating, exhaustion, rashes, headache and cramps (Table 4). Heat stroke was not reported. Heat can also increase workers' risk of injuries, as it may result in sweaty palms, foggedup safety glasses, and dizziness. It may also reduce functioning responsible for reasoning ability, creating additional hazards. However, managers' knowledge about the effects of heat on human health was poor (only $32.3 \%$ had knowledge).

\subsection{Productivity Loss}

Floriculture workers who are working in the greenhouses are particularly affected by heat stress, because of the intensive physical work and the hot and humid working conditions. However, knowledge on the topic was limited. Overall, $64.5 \%$ of the managers and $54.1 \%$ of the workers reported that heat stress in the greenhouses has no effect on work and productivity (Table 5). Only $35.5 \%$ of the managers and $18.4 \%$ of the workers perceived that occupational heat stress has a negative impact on their work and productivity. $26 \%$ of the workers reported that they do not know the effect of heat stress on work and productivity. However, workers reported that very hot weather makes their work more difficult and uncomfortable.

Hourly WBGT average WBGT index values reach levels beyond the international standard safe work values (ISO 7243:1989) during 10:00 AM to 3:00 PM (Table 6). The median WBGT index was $25.5^{\circ} \mathrm{C}$ and ranged from $18.1^{\circ} \mathrm{C}$ to $31.5^{\circ} \mathrm{C}$ inside the greenhouses.

Flower farms in the highlands with steel structures experience heat stress only for three hours (from 11:00 to 14:00) while flower farms in the midlands are challenged for 6 - 7 hours (from 10:00 to 16:00). On the other hand, the temperature and humidity of farms in the lowlands that are producing cuttings are fully controlled with automated system and they are not exposed to heat stress and productivity losses due to heat stress the whole day.

Table 4. Self-reported heat stress induced health problems by workers in the floriculture sector.

\begin{tabular}{cccccc}
\hline \multirow{2}{*}{ No } & Health Impacts & \multicolumn{3}{c}{ Intensity } \\
\cline { 3 - 5 } & & Never & Little & Moderate & High \\
\hline 1 & Sweating & $19(6.2)$ & $31(10.2)$ & $58(19.0)$ & $195(63.9)$ \\
2 & Exhaustion & $25(8.2)$ & $26(8.5)$ & $68(22.3)$ & $184(60.3)$ \\
3 & Rash & $166(54.4)$ & $71(23.3)$ & $41(13.4)$ & $26(8.5)$ \\
4 & Headache & $83(27.2)$ & $58(19.0)$ & $55(18.0)$ & $106(34.8)$ \\
5 & Cramps & $214(70.2)$ & $48(15.7)$ & $19(6.2$ & $23(7.5)$ \\
\hline
\end{tabular}


Table 5. Perceived knowledge on the effect of heat on work productivity by managers and workers.

\begin{tabular}{cccc}
\hline \multirow{2}{*}{ Perceived knowledge } & Answer & \multicolumn{2}{c}{ Respondent } \\
\cline { 2 - 4 } Effect on Work and Productivity & & Managers & Workers \\
\hline Yes & No & $11(35.5)$ & $56(18.4)$ \\
Effect on income & No change & $20(64.5)$ & $79(25.9)$ \\
\hline
\end{tabular}

Table 6. Summary of Hourly WBGT index average values by time.

\begin{tabular}{|c|c|c|c|c|c|c|c|c|c|c|c|}
\hline \multirow{2}{*}{ Farm $^{\star *}$} & \multicolumn{8}{|c|}{ Active Working Time } & \multicolumn{3}{|c|}{ Calculated Productivity loss } \\
\hline & 9:00 & 10:00 & 11:00 & $12: 00^{*}$ & 13:00 & 14:00 & $15: 00$ & $16: 00$ & Time & $\% * * *$ & Loss in $E T B^{* * * *}$ \\
\hline HL1 & 22.8 & 25.8 & 26.5 & 27.2 & 27.1 & 25.8 & 25.2 & 22.41 & $11-14$ & 2.2 & 13,090 \\
\hline HL2 & 19.4 & 22 & 23.6 & 24.5 & 24.6 & 23.1 & 19.4 & 18.15 & None & 0.0 & 0 \\
\hline ML1 & 24.3 & 29.1 & 31 & 31.5 & 31.3 & 30.6 & 28.6 & 27.17 & $10-16$ & 19.1 & 120,330 \\
\hline ML2 & 25.5 & 27.6 & 28.7 & 30.5 & 29.8 & 30 & 29.1 & 28.10 & $10-16$ & 13.5 & 83,869 \\
\hline LL1 & 21.5 & 23.5 & 25.4 & 26.3 & 26.7 & 26.4 & 25.2 & 23.16 & $13-15$ & 0.8 & 10,906 \\
\hline LL2 & 19.6 & 21.7 & 23.4 & 24.3 & 25.2 & 24.5 & 23.4 & 22.46 & None & 0.0 & 0 \\
\hline Avg & $22.2(2.5)$ & $25.1(3.1)$ & $26.3(3.1)$ & $27.4(3.0)$ & $27.5(2.6)$ & $26.7(3.0)$ & $25.2(3.6)$ & 23.6 & & & \\
\hline
\end{tabular}

${ }^{\star}$ The shade (12 to 13 ) is assumed to be lunch break and productivity losses are not calculated. ${ }^{*} \mathrm{HL}=$ Highland, ML $=\mathrm{Midland}$ and $\mathrm{LL}=$ Lowland farms studied. ${ }^{* *}$ Productivity losses $=5 \%$ when the WBGT index increased by $1^{\circ} \mathrm{C}$ above $\mathrm{TLV}\left(26^{\circ} \mathrm{C}\right){ }^{* * * *} \mathrm{Monthly}$ losses due to OHS in Ethiopian Birr taking the average wage of a worker is 1750 ETB per month.

The calculated productivity loss for HL1 farm is about $2.2 \%$ during the two hot hours (Table 6). ML1 and ML2 farms are exposed to a productivity loss of $19 \%$ and $13.5 \%$, respectively, during $10: 00$ to $16: 00$ hours from all the workers. The losses in terms of monetary values due to heat stress range from 0 to 120,000 ETB per month. However, only $26 \%$ of workers said their income was reduced by heat because of missing work.

\subsection{Coping Mechanisms}

Of the participants, $45.2 \%$ of the managers and $24.9 \%$ of the workers reported that there are no directives about working in hot conditions while $16 \%$ of the managers and $67.5 \%$ of the workers do not know whether there is such a directive for their companies (Table 7). In addition, the majority of the managers reported that they do not inform their workers about the level of heat in the greenhouses. Directives to reduce heat and protection from heat stress in the greenhouses are not available. 
Table 7. Perceptions on coping mechanisms from heat stress by managers and workers in the floriculture industry.

\begin{tabular}{|c|c|c|c|}
\hline & & Managers & Workers \\
\hline \multirow{3}{*}{ Directives about working in hot condition } & Yes & $12(38.7)$ & $20(6.6)$ \\
\hline & No & $14(45.2)$ & $76(24.9)$ \\
\hline & Do not know & $5(16.1)$ & $206(67.5)$ \\
\hline \multirow{2}{*}{ Directive to reduce heat in workplace } & Yes & $16(51.6)$ & \\
\hline & No & $13(41.9)$ & \\
\hline \multirow{2}{*}{ Measurement of heat in the workplace } & Yes & $17(54.8)$ & \\
\hline & No & $14(45.3)$ & \\
\hline \multirow{2}{*}{ Are the workers informed about hot weather } & Yes & $8(25.8)$ & \\
\hline & No & $22(71.0)$ & \\
\hline \multirow{2}{*}{ Directives about protection from heat stress } & Yes & $10(32.3)$ & \\
\hline & No & $19(61.3)$ & \\
\hline
\end{tabular}

\section{Discussion}

Climate change is emerging as one of the major threats to development across Africa. The rise in global temperatures caused by climate change will also make occupational heat stress more common particularly for countries in the tropics. Such excess heat increases workers' occupational risks and vulnerability; it can lead to heatstroke and, ultimately, even to death. The risk of exposure to extreme heat is expected with climate change. Low and middle-income countries within the tropical and sub-tropical regions are particularly at risk. Workers in these countries performing manual labour are the most vulnerable and their employers may be forced to considerably reduce their work time because of excessive heat [13] [21]. Maintaining a core body temperature of around $37^{\circ} \mathrm{C}$ is essential for continued normal body function [13]. Excessive heat during work creates occupational health risks; it restricts a worker's physical functions and capabilities, work capacity and productivity.

WBGT index levels $\left(18.1^{\circ} \mathrm{C}\right.$ to $\left.31.5^{\circ} \mathrm{C}\right)$ in the greenhouses are significantly higher than outdoors as greenhouses prevent thermal radiation from escaping and the air mass inside greenhouses is so much smaller than the air mass outdoors. In the low-altitude area, it reaches levels beyond the international standard safe work values (ISO 7243:1989) during the period from 10:00 AM to 3:00 PM. The wooden greenhouse structure material has also showed a significantly lower heat index as compared with that of steel structures. Overall workers in cut-flower greenhouses are exposed to higher than recommended WBGT Index $\left(26^{\circ} \mathrm{C}\right)$ for 3 - 6 working hours daily but differently across different agroecologies, product types and greenhouse materials. However, the level of understanding on the impact of heat exposure on health and productivity loss by both managers and workers is uniformly low.

Thus, occupational heat stress (excessive workplace heat) is an occupational 
health and productivity hazard in the floriculture greenhouses, especially in the mid and lowland parts of Ethiopia. Workers in the greenhouses are regularly exposed to warm to hot working conditions for some time during thy day. Because of the physically demanding nature of work in the sector, workers often experience considerable excess heat, increasing their risk of heat stress in even moderately warm conditions. In the current pilot study, while sweating, exhaustion, rashes, headache and cramps were reported, heat stroke was not.

In order to measure worker productivity, it is required that the study participants achieve measurable outputs at the end of each day. However, this study did not measure work outputs on an individual basis and productivity loss due to heat stress was estimated as the percentage of direct work time decreasing by $5 \%$ when the WBGT increased by $1^{\circ} \mathrm{C}$ above TVS following Sahu et al. [22] (5\%) [20] and Kjellstrom et al. (20\%) [13].

Sahu et al. [22] investigated high heat exposure during agricultural tasks in India and observed that worker productivity reduced by approximately $5.14 \%$ for each $1^{\circ} \mathrm{C}$ increase in WBGT above $26^{\circ} \mathrm{C}$ [22]. They developed a linear regression model for loss in productivity that can be calculated for all WBGT values greater than or equal to $26^{\circ} \mathrm{C}$ and less than $42.4^{\circ} \mathrm{C}$ (above $42.4^{\circ} \mathrm{C}$ the decline is 100 (Decline in labour productivity $(\%)=100-((-5.14 *$ WBGT $)+218)$ [22]). On the other hand, Li et al. (2016) observed a $0.57 \%$ decrease in productivity for every $1^{\circ} \mathrm{C}$ rise in WBGT above $25^{\circ} \mathrm{C}$, for re-bar workers (heavy labour) in (Decline in labour productivity $(\%)=100-((-0.57 *$ WBGT $)+106.16))$ [23]. Gosling, et al. [24] work on climate change and productivity of Chinese construction, concluded that Li et al. [23] model can be scaled-up for all types of labour, the general population, and across Europe [24]. They assumed that the estimated impacts for outdoor and indoor labour productivity are applicable to all economic sectors that involve moderate to intense indoor or outdoor working, including agriculture, construction, and factory working [24].

Occupational heat exposure guidelines are based on WBGT state maximum heat exposures in jobs at different work intensities (NIOSH, 1986; ISO1989). As per the ISO 7243 standard the proportions of work hours during which workers need to take rest periods, assuming a medium work intensity in the greenhouses and WBGT readings, cut-flower farms in the midlands and lowlands should provide $25 \%$ rest/hour between 10:00 to $16: 00$ in order to avoid the core body temperature exceeding $38^{\circ} \mathrm{C}$ for an average worker. The ISO international standard $(\mathrm{Nr} 7243,1989)[18]$ recommends that regular rest periods are taken when the heat index is above $26^{\circ} \mathrm{C}$ (WBGT) in the context of heavy physical work if clinical health effects are to be avoided.

There are many ways to manage heat stress at work, including preparation of directives about working in hot conditions, reductions in heat exposure, improved access to hydration, and providing orientation of attitudes towards working in the heat to both the managers and workers. Productivity loss due to heat stress in our study was estimated as the percentage of direct work time decreasing by $5 \%$ when the WBGT increased by $1^{\circ} \mathrm{C}$ above TLV following Sahu et.al. 
[22] (5\%) and Kjellstrom et al. [12] [13] (20\%). It is assumed workers do not achieve work targets, due to fatigue/exhaustion, sickness/hospitalization, and/or wages lost due to heat or heat-related illnesses.

The slowing down of work as an adaptation during severe heat exposure is labelled "autonomous adaptation" by climate change researchers [25]. Analyses of the annual losses of daylight work hours due to excessive heat exposure [12] [13] show substantial losses in many regions of the world. The losses in the 19802009 period are already up to 5\% - 7\% for several regions. Estimates for 2030 showed that the worst affected regions would be South Asia and West Africa, and ten regions in Asia, Africa and Latin America have more than 2\% of work hours lost by this date.

The Ethiopian Horticulture Producer Exporters Association Code of Practice is the result of an initiative taken by the sector to introduce a voluntary system of continuous professional and technical development, monitoring and self-regulation into the sector [9]. It is designed to address market and civil society concerns about standards for social and environmental performance in the sector. To prevent heat-related illnesses, managers and workers should have adequate knowledge about the public health impacts of heat and the development of heat prevention strategies.

The Code of Conduct provides useful guidance about standards and systems to guide the sustainable development of the sector. Farms' performance and commitment towards sustainability have improved as a result of the training and support provided by the Association and Stakeholders. However, the code of practice which is in place now does not consider the occupational heat stress issues. Appropriate training and guidelines will help in mitigating the effects of excessive heat exposure on the health and productivity of floriculture workers. Designing heat prevention strategies (such as making drinking water readily available, establishing work-rest regimes) to be incorporated in the code of conduct is vital in accordance with ISO 7243.

\section{Conclusions}

Occupational heat stress is potentially a major problem with health and productivity in the floriculture industry. This study shows that the WBGT index values reach levels beyond the international standard safe work values (ISO 7243:1989) from 10:00 AM to 4:00 PM and occupational heat stress is of great concern of health and productivity losses.

The level of managers' understanding regarding occupational heat stress impacts on health and productivity losses is low. However, the majority of workers have recognized that heat stress is a problem with their health and can create productivity losses but without impact on their income.

The heat stress in the greenhouses is associated with a spectrum of heatrelated illnesses, including heat stroke, which can lead to death. The common health effects mentioned include sweating, exhaustion, rashes, headache and cramps that need the attention of the managers. 
Labour productivity is estimated to be reduced on the order of $0 \%-19 \%$ across agroecologies. Climatic heat affects labour productivity, primarily through dehydration. It is in the interests of both employers and employees to limit heat exposure and prevent dehydration. Dehydration may lead to heat exhaustion and increase the risk of heat stroke. It is important, therefore, that management ensures the availability of sufficient drinking water and that workers are made aware of the need to drink frequently when the WBGT index is over $26^{\circ}$ to avoid dehydration and renal diseases.

The findings suggest a need to strengthen workers' heat risk awareness and refine current heat prevention strategies in a warming climate. Well-targeted heat related educational programmes and training should be made for managers and supervisors as well.

Further analysis of the health and economic impacts of climate change in the workplace is needed to understand the full impacts of current and future climate for the different agroecologies and farming systems for effective national adaptation and mitigation policies.

\section{Implications and Recommendations}

The impact of increasing heat on working people is a key feature of climate change and can undermine efforts to reduce poverty and to achieve the Sustainable Development Goals (SDGs) of the country. Preventive policies and actions are therefore needed at local and national levels. Increasing worker safety and productivity is achievable by controlling heat exposure. However, policy makers and managers often disregard heat stress as an occupational hazard. This study and other related studies have suggested that, it can be greatly reduced with proper work organization and education.

Table 8. Suggested recommendations to reduce heat stress in the floriculture greenhouses based on a pilot study.

\begin{tabular}{|c|c|c|}
\hline & Intervention Categories & Suggested Activities \\
\hline 1 & $\begin{array}{l}\text { Engineering } \\
\text { related issues }\end{array}$ & $\begin{array}{l}\text { - Increase ventilation/air conditioning during } 10 \mathrm{am}-4 \mathrm{pm}) \\
\text { - Promote the use of wooden greenhouse structure (e.g. Bamboo) } \\
\text { - Install more cooling fans keeping in mind the optimum temperature for flowers }\left(28^{\circ} \mathrm{C}\right)\end{array}$ \\
\hline 2 & $\begin{array}{l}\text { Management/ } \\
\text { administrative related } \\
\text { issues }\end{array}$ & $\begin{array}{l}\text { - Schedule working hour earlier or later in the day during hot seasons } \\
\text { - Use work/rest schedules following ISO standard } \\
\text { - Make water readily available to workers, and encourage them to drink frequently when hot }\end{array}$ \\
\hline 3 & $\begin{array}{l}\text { Training and information } \\
\text { related issues }\end{array}$ & $\begin{array}{l}\text { - Train managers and workers regarding causes and consequences of OHS } \\
\text { - Train managers on the steps and actions to be taken when workers are exposed to heat or cold } \\
\text { - Enhance awareness of workers (especially to women) regarding OHS }\end{array}$ \\
\hline 4 & Policy related measures & $\begin{array}{l}\text { - Address the occupational heat stress issues in the existing Code of Conduct } \\
\text { - Develop detailed directives to reduce the impact of OHS that enhances workers productivity and } \\
\text { their health } \\
\text { - Ensure the availability of sufficient water and that workers are made aware of the need to drink }\end{array}$ \\
\hline
\end{tabular}


The most effective way to prevent heat-related illness and productivity losses is to reduce heat stress in the workplace and create awareness about heat related diseases and work productivity. To this effect, multiple actions (engineering, management, training and policy related recommendations) have to be implemented by Ethiopian Horticultural Producers and Exporters Association (EHPEA) and farm owners to mitigate heat stress and loss of productivity (Table 8). Designing and implementing these heat prevention strategies and incorporating them in the code of conduct is in the interests of both employers and employees to bring sustainable growth in the floriculture industry in Ethiopia.

\section{Future Research}

As heat-related effects are new phenomena in Ethiopia and other sub-Saharan African countries, more research is needed on climate change impacts on public health in different community groups and on developing heat-prevention guidelines appropriate to both indoor and outdoor agricultural workers. Further fullfledged studies in the agriculture sector, which is the major economy of the country employing $85 \%$ of the working population, are highly needed to reduce heat-related risks and measure the current government heat-prevention policies.

\section{Acknowledgements}

This work was supported by NIH Fogarty International Center, NIEHS, CDC/ NIOSH, Canada's IDRC, GACC. Grant \# 5R24 TW009552; 5R24 TW009548; 1U01TW010094; 1U2RTW010125. The Ethiopian Horticulture Producers and Exporters Association (EHPEA) have provided technical assistance throughout the implementation period of this research. We would like to thank the managers and workers of the 6 greenhouses for their assistance and cooperation during the field work.

\section{Conflicts of Interest}

The authors declare no conflicts of interest regarding the publication of this paper.

\section{References}

[1] IPCC (2007) Climate Change 2007: Impacts, Adaptation and Vulnerability. Intergovernmental Panel on Climate Change 2007, Cambridge, UK. https://doi.org/10.1017/CBO9780511546013

[2] IPCC (2014) Impacts, Adaptation and Vulnerability. IPCC, Cambridge, UK.

[3] ILO (2019) Working on a Warmer Planet: The Impact of Heat Stress on Labour Productivity and Decent Work. International Labour Office, Geneva

[4] CRGE (2011) Ethiopia's Climate Resilient Green Economy: Green Economy Strategy. Addis Ababa, Federal Democratic Republic of Ethiopia.

[5] Conway, D. and Schipper, E.L.F. (2011) Adaptation to Climate Change in Africa: Challenges and Opportunities Identified from Ethiopia. Global Environmental Change, 21, 227-237. https://doi.org/10.1016/j.gloenvcha.2010.07.013 
[6] Simane, B., Zaitchik, B.F. and Foltz, J.D. (2016) Agroecosystem Specific Climate Vulnerability Analysis: Application of the Livelihood Vulnerability Index to a Tropical Highland Region. Mitigation and Adaptation Strategies for Global Change, 21, 39-65. https://doi.org/10.1007/s11027-014-9568-1

[7] McKinnon, M., Buckle, E., Gueye, K., Toroitich, I., Ionesco, D., Mach, E., et al. (2016) Climate Change and Labour: Impacts of Heat in the Workplace. UNDP, ILO, WTO, UNI, ITYUC et al., $29 \mathrm{p}$.

[8] KiShin, H., Lieth, J.H. and Kim, S.-H. (2000) Effects of Temperature on Leaf Area and Flower Size in Rose. III International Symposium on Rose Research and Cultivation. Acta Horticulturae, 547, 185-191.

https://doi.org/10.17660/ActaHortic.2001.547.22

[9] EHPEA (2010) Ethiopian Horticulture Producers and Exporters Association (EHPEA) Code of Practice Implementation Report. EHPEA, Addis Ababa.

[10] EHPEA (2018) Export of Horticulture in Ethiopia, Addis Ababa. 2018. In: Association EHPaE, Ed.,. Addis Ababa: Ethiopian Horticulture Producers and Exporters Association 2018, Ethiopian Horticulture Producers and Exporters Association, Addis Ababa.

[11] Parsons, K. (2014) Human Thermal Environments: The Effects of Hot, Moderate, and Cold Environments on Human Health, Comfort, and Performance. CRC Press, Boca Raton. https://doi.org/10.1201/b16750

[12] Kjellstrom, T., Kovats, R.S., Lloyd, S.J., Holt, T. and Tol, R.S.J. (2009) The Direct Impact of Climate Change on Regional Labor Productivity. Archives of Environmental \& Occupational Health, 64, 217-227. https://doi.org/10.1080/19338240903352776

[13] Kjellstrom, T., Briggs, D., Freyberg, C., Lemke, B., Otto, M. and Hyatt, O. (2016) Heat, Human Performance, and Occupational Health: A Key Issue for the Assessment of Global Climate Change Impacts. Annual Review of Public Health, 37, 97-112. https://doi.org/10.1146/annurev-publhealth-032315-021740

[14] Staal Wästerlund, D. (2018) Managing Heat in Agricultural Work: Increasing Worker Safety and Productivity by Controlling Heat Exposure. FAO, Rome.

[15] NIOSH (2018) NIOSH Criteria for a Recommended Standard: Occupational Exposure to Heat and Hot Environments. National Institute on Drug Abuse, USA.

[16] Bouchama, A. and Knochel, J.P. (2002) Heat Stroke. The New England Journal of Medicine, 346, 1978-1988. https://doi.org/10.1056/NEJMra011089

[17] Schulte, P.A. and HeeKyoung, C. (2009) Climate Change and Occupational Safety and Health: Establishing a Preliminary Framework. Journal of Occupational and Environmental Hygiene, 6, 542-554. https://doi.org/10.1080/15459620903066008

[18] ISO (1989) Hot Environments-Estimation of the Heat Stress on Working Man, Based on the WBGT-Index (Wet Bulb Globe Temperature). International Standards Organization, Geneva.

[19] Kjellstrom, T., Gabrysch, S., Lemke, B. and Dear, K. (2009) The "Hothaps" Programme for Assessing Climate Change Impacts on Occupational Health and Productivity: An Invitation to Carry Out Field Studies. Global Health Action, 2, Article No. 2082. https://doi.org/10.3402/gha.v2i0.2082

[20] Yi, W. and Chan, A.P.C. (2017) Effects of Heat Stress on Construction Labor Productivity in Hong Kong: A Case Study of Rebar Workers. International Journal of Environmental Research and Public Health, 14, Article No. 1055. https://doi.org/10.3390/ijerph14091055

[21] Nilsson, M. and Kjellstrom, T. (2010) Climate Change Impacts on Working People: 
How to Develop Prevention Policies. Global Health Action, 3, Article No. 5774. https://doi.org/10.3402/gha.v3i0.5774

[22] Sahu, S., Sett, M. and Kjellstrom, T. (2013) Heat Exposure, Cardiovascular Stress and Work Productivity in Rice Harvesters in India: Implications for a Climate Change Future. Industrial Health, 51, 424-431.

https://doi.org/10.2486/indhealth.2013-0006

[23] Li, X., Chow, K.H., Zhu, Y. and Lin, Y. (2016) Evaluating the Impacts of HighTemperature Outdoor Working Environments on Construction Labor Productivity in China: A Case Study of Rebar Workers. Building and Environment, 95, 42-52. https://doi.org/10.1016/j.buildenv.2015.09.005

[24] Gosling, S.N., Zaherpour, J. and Ibarreta, D. (2018) PESETA III: Climate Change Impacts on Labour Productivity. Publications Office of the European Union, Luxembourg.

[25] Ebi, K.L., Smith, J.B. and Burton, I. (2005) Integration of Public Health with Adaptation to Climate Change. Taylor \& Francis, New York. 